\title{
Heritage Language Maintenance and Ethnic Identity in Virtual Communication among Javanese Basketball Coaches in Indonesia
}

\author{
Deny Efita Nur Rakhmawati ${ }^{1, *}$, Dwi Cahyo Kartiko \\ ${ }^{I}$ UIN Maulana Malik Ibrahim Malang, Indonesia \\ ${ }^{2}$ Universitas Negeri Surabaya, Indonesia \\ *Corresponding author.Email: denyefita.nr@bsi.uin-malang.ac.id
}

\begin{abstract}
The promotion of nationality and technology have drained Javanese as the ethnic language in Indonesia as a multilingual country. This study, therefore, explores the Javanese as an ethnic marker and identity in virtual communication. The data were collected via semi-structured interviews and observation in the WhatsApp group of East Java basketball coaches. The findings demonstrate that the Javanese language is still valued as an ethnic marker and Javanese people believe that its maintenance reflects their identity construction. However, its divergence cannot be ceased as the process of maintaining the language clashed with other ethnic groups.
\end{abstract}

Keywords: heritage language maintenance, ethnic identity, virtual communication, basketball coaches

\section{INTRODUCTION}

As one of Indonesia's most prominent speakers, the Javanese heritage language [1] is endangered [2] in showing its ethnic origin. The drastic decline in the numbers of Javanese speakers has been intense in the last three decades, was around 3\% decline among 25 49 years old during the previous ten years [3] and around 70 million from 95 million population in 2020 [4]. This battle has risen since the stipulation of Indonesian as the official national language in all aspects of the domain [5], the high mobility and increasing middle-class groups [6], and the influence of globalization, which is dominated by the use of English [7]. Another new factor is contributed by the pandemic lately, where all activities are pioneered by the virtual communication and certainly Indonesian and are dominantly used. These factors indicate that the large numbers of Javanese speakers cannot protect the existence of Javanese [8].

Furthermore, these factors have dropped the roles of Javanese as the ethnic language among the other various ethnic groups and ethnic language communities in Indonesia [3]. With less exposure to Javanese, less active speakers would enhance their background knowledge and resources. Moreover, it would intrigue more generations to run away from expanding their minor language as there are limited development facilities. Javanese is also transmitted predominantly within the family rather than any other community. Besides, Javanese has served more as spoken than the written one, as many active speakers meet some challenges to read the Javanese alphabet.

Javanese as their language background is also a determination of selves, bringing up their ethnicity. A language is considered the central aspect of culture and has a potential dimension of how individuals may represent their identity [9]. Maintaining Javanese as a heritage language in a multicultural country like Indonesia is considered the essential cultural identity marker of ethnic minority groups [10]. Moreover, a study spotted that parents' attitude about Javanese as ethnic language and ethnicity is asymmetrical. Still, their desire to transmit their heritage language is 
symmetrical with their children's high proficiency scores [3]. Another study in Indonesia conflicted that those who can speak in their ethnic language are more confident in showing their ethnic identity. Those who cannot speak any would feel more confused with their ethnic identities [11].

Besides, many exclusive works have pinpointed how ethnic languages in many other countries related to ethnic identities. Studies in Europe diagnosed a shift of ethnic identity construction involving a process of heritage language among the inter-generation between parents and children [12]. It was supported by studies in America that distinguished how the fluency in delivering a heritage language has played the crucial act in forming the ethnic identity among the second generation of Mexican adolescents but not for the second generation of Chinese in the USA [13].

Those previous studies talk primarily about the influence of adults on the younger generation. Therefore, there is an assumption that those of very productive ages take a significant role in maintaining Javanese, as people with different sociolinguistics dynamics within the community might potentially influence its language vitality [3]. However, since technology dominates the life agenda nowadays, adults could provide experience and various resources to surrounding environments in virtual communication. In other words, when adults use Javanese in a particular group of online communities, it could be adapted and accustomed to real-life communication. The rise of virtual communication faces the opportunity to use Javanese to build their mediatized room to take more actions than in the traditional communication [14] [15].

Furthermore, virtual communication would put the endangered Javanese in a better position to be continuously used, thus settling up a new chapter, modes of communication, and developing its written varieties which is previously spoken only language [16]. The appearance of Javanese in virtual communication is another level of promotion to make it more visible and accessible [17]. Therefore, it delivers its priority in this modernity so that all generations would be inspired to maintain such language.

It is of a public nature that virtual communication might happen when immediate context, impact, and affection connect them [18]. In other words, virtual communication is possible to continue when there is a silver lining in connecting the dots among them. People who engage in virtual communication mostly happen among those who have connections in offline relationships and those who just knew online. Bearing that in mind, technology builds essential sides of how people live, access, and benefit from it in the aspect of their senses of selves [18], which then reflects the way they portray themselves online. At the same time, it could be summarized that what they represent online is much related to their identities offline [19].

One of the interesting points in an online group of virtual communication is when the groups consist of adult people from different ethnic groups. For example, one of the various ethnic participants of the online group is a WhatsApp group of East Java Basketball coaches. The coaches are people from many ethnic groups with different ethnic languages. In this case, the use of ethnic language by each ethnic group in the group is questioned as it is related to the way they reflect their ethnic identity.

Many research has talked about these interrelations in online media. For example, a study presented that writing in a heritage language online would mitigate their Chinese heritage writing anxiety. Furthermore, they became more productive, limiting their avoidance behaviors [20]. Another work showed that Facebook is a suitable medium for maintaining heritage language as it provided a mediatized space for bilingual users and regional identity [21]. These significant works have already provided evidence of the benefits of online media in interconnecting heritage language maintenance and identity construction. Yet, little is known about dynamic virtual communication in an intensive WhatsApp group communication. Therefore, further investigation is needed, especially in the contexts of the heritage language in their homeland [3]. This particular online community is genuinely connected to the real-life profession.

Within this phenomenon in consideration, this present study aims to fill the gap by observing whether the Javanese adults of Basketball coaches attitudes in the WhatsApp group shape the Javanese identity as an ethnic marker and proficiency in virtual communication [3]. In addition, this study also attempts to examine how Javanese speakers use virtual communication. 


\section{LITERATURE REVIEW}

A heritage language is a language other than the dominant standard language in all aspects of life [21]. It is generally described as immigrant, colonial, and indigenous languages. Javanese is acknowledged as the indigenous or ancestral and minority language [3]. Moreover, language is essential in forming the speakers' thinking and who they are [11]. Speaking a specific language also reflects the speaker's identity [22]. Identity differentiates one from another, and it is a developmental process that might change over time [23]. It is continuously in the transformation process and adapts based on the situations [23].

[23] lists some stages of identities formation: micro, meso, macro, and global identities. First, the micro stage defines ourselves and our point of view. It is based on their observations, inferences about who they are, and evaluations [24]. This stage is also about the interaction between individuals and how others act toward them. Then, the meso stage is related to perceiving people's families and cultures. Next, the macro ones are between and from a more significant point of view which interrelates people and groups. Last, interconnecting between people and groups in a bigger perspective is categorized in the global stage of identity. Thus, there is a broad connection between language and identification.

Another critical factor in a language related to identity is the social setting. First, the language used defines the ethnic group and the social level [11]. Then it relates to ethnic identity, a dynamic and multidimensional structure that intends to represent one's identity or self as a part of an ethnic group [22]. Indeed, the established sense of self as a part of an ethnic group representative involves positive feelings about oneself and others [24].

Furthermore, the degree of vitality of a particular ethnic group resolves the social behaviors in the intergroup interactions, including status (economic, social, socio-historical, and language status), demography (distribution and number of the population), and institutional support (formal and informal) [3], for example, Javanese has a high ethnolinguistic vitality in language status, distribution, and population.

It is also taken for granted that language is a system that is unlikely to be transformed by the way it is used by the media [21]. However, media use shapes how communication runs and how language is used. The drastic language changes appear in the rise of computer-mediated communication (CMC) [15]. Since then, all communication conducted through CMC has been known as virtual communication. Virtual communication enables the speakers to create online communities [14], a far more interactive space.

\section{METHOD}

This study adopts a descriptive qualitative methodology. It tries to describe a phenomenon on the heritage language used and how their attitudes in using the language influence their ethnic identity construction. 15 Javanese basketball coaches between the ages of 25 to 45 years old were recruited as the study participants. They had fulfilled the criteria of speaking Javanese and actively communicating in the WhatsApp group of East Java Basketball coaches. Deliberating the study's ethics, all participants were briefed on the study's scopes and objectives.

The data were collected through an observation on written virtual communication on WhatsApp group and semi-structured interviews in three months to allow the participants to share information and freedom to express their opinions [25]. Hence, the questions were formatted to ask about their heritage language use by adopting and simplifying the Multigroup ethnic identity measure (MEIM) survey consisting of self-identification and ethnicity, ethnic behaviors and practices, affirmation and belonging, and identity achievement [26]. The interviews were conducted in Bahasa Indonesia and recorded in audio recordings.

Then, a thematic analysis was borrowed to analyze the data since the method allows the researchers to interpret the data based on the in-depth examination. The analysis steps were understanding the data, creating initial codes, searching for themes throughout the data, reviewing all of the themes, defining and naming themes, and finally producing the reports [27] based on the theory of identity and heritage language.

\section{RESULTS AND DISCUSSION}

The results of the observation and interviews are presented in two sub-sections: attitudes on the relation between Javanese use and ethnic identity marker and 
attitudes on Javanese and its use in virtual communication.

\subsection{Attitudes on the Relation between Javanese Use and Ethnic Identity Marker}

Eleven of fifteen participants agreed that the Javanese language was immensely valued as an ethnic identity marker. It indicated that their selfidentification as Javanese ethnic group members was related to their ability to speak in the Javanese language. However, the other four participants argued that the Javanese language was not the indicator of being a part of the ethnic group. In other words, they proposed the idea that using other languages is still categorized as becoming the members of the ethnic group. Moreover, they claimed to belong to a Javanese ethnicity, but it did not always mean they spoke in the Javanese language.

Besides, those eleven participants believed that using the Javanese language reflected their selfbelonging to their ethnic group. The sense reflects their high confidence when they use the Javanese language. They also said it was easier for them to communicate in Javanese. In addition, they could use many vocabularies not found in the national language, Bahasa Indonesia, or even other ethnic languages. These statements were in line with [28] stating that a heritage language indexes ethnic memberships and simplifies the sense of belonging.

In addition, seven of the participants figured out that Javanese was identic with high values and norms. It could be figured out from the levels of Javanese language: ngoko, madya, and krama. Each level was used based on the age and status of the interlocutors. They need to use ngoko Javanese when to their mates or inferior coaches. Madya was used to the older coaches but still in the same level or status.

On top of that, krama should be used when talking to their superiors or senior coaches. The different levels of Javanese here pointed out that its existence became very meaningful as it carries norms, values, and feeling to an ethnic group [3]. Additionally, the other four participants configured that there was nothing special about Javanese. All languages certainly have values as it bridges the users to convey their meanings in the communication.
Furthermore, every participant did not always master the speech levels of the Javanese language. Five of the participants were very fluent in those three levels, four of them were fluent in ngoko and madya, and six were good in ngoko only. These different proficiencies on speech levels did not mean that they had a different level of ethnic identity. All of them were Javanese, able to speak in the Javanese language and express themselves as Javanese. Their proficiencies were different because they were getting used to exposure to certain levels of Javanese only. It was supported by [29] that younger generations tended to escape from speech levels as it needed grammatical modification and politeness, different vocabularies acquisition, and cultural modification.

Talking about politeness, the East Java citizen chose the ngoko speech level, considered the lowest one. They approved it as the expression of intimacy, affection, and hospitality. The closer the relationship, the lower the speech level. This belief might reflect that Javanese from East Java was quite challenging and robust compared to the other parts of Java. In other words, choices of words mirrored the ethnic identity.

In contrast, the words choices in different speech levels of Javanese reversed the action of politeness; for example, using the word eat could be expressed in three different situations with three different levels of politeness. Mangan is the ngoko speech level for eat was considered impolite when they used it to the older coaches or the head of the coaches. Three of Javanese coaches who could not recognize the differentiation use of mangan, nedho, and dhahar were known that they could not fully represent their identities as Javanese. As said by [11] a heritage language proficiency does not simply work for verbal communication purposes but also represents their ethnic identity.

The participants disputed that the communication among coaches was more casual, so they were adjustable to use any speech level to any age's coaches. In this case, these basketball coaches primarily work on the open field, so they were forced to be more flexible, open-minded, and fluid. Thus, the attitude to manage Javanese's use in such a way would resonate with their identities as Javanese and as basketball coaches. 
However, their incapability was indicated that they did not do it on purpose. Most of them just did not know how and when to use it properly. It was found among the youngest area of age's participants, from 25 to 30 years old. It was also intended to acknowledge that the participants were faced with minimum contact and exposure of Javanese in their schools at their younger ages. In informal families' situations, they were disclosed to the Javanese use situation. They who lived in villages tended to communicate in Javanese compared to those in the cities. School also just put Javanese in a two-hour subject per week. Javanese was not placed at the heart of education [30], just like the global trend of English as an international language. Families and schools believed that their younger generations did not call for the need of Javanese as it was considered the additional subject in the curriculum. Their success was not based on their proficiency in Javanese as a heritage language.

These two conditions were initiated since the colonial era, in which every citizen should have one nationality, one language, and one homeland, that was Indonesia. It put aside the varieties of ethnic languages and identities and built a strong base of a shared identity known as national identity [3].

\subsection{Attitudes on Javanese and Its Use in Virtual Communication}

Globalization established virtual communication for people worldwide, including the basketball coaches in East Java. The professional basketball coaches conducted their coordination, meetings, and discussion on the basketball rules of the game through virtual communication in a WhatsApp group. Virtual communication should be seen as writing, not spoken, combined with several visual means [21].

All participants argued that they inspired virtual communication by using Javanese to initiate almost all communication topics among the Javanese members. Thirteen participants stated that they shifted the language into Indonesian when other coaches from other ethnic groups, such as Madurese, Padangnese, Sundanese, Banjarese, Acehnese, Balinese, etc., joined the communication. Three of them were sometimes still used the very well-known terms in Javanese during the multi-ethnic group's communication, such as nggih, piye, rek, etc. It was identified that these participants still recruited these Javanese terms to convey their messages in the virtual communication. They thought that Javanese would provide more underlining statements of being Javanese, and they argued that almost all coaches from different ethnic groups would understand these terms. These old words and phrases suggested an active contribution to maintenance efforts [21].

Moreover, when there was discussion in the group, fifteen participants were very active and responded to the discussion. Though the discussion was primarily conducted in Indonesian, five participants customarily commented and explained in mixed languages between Indonesian and Javanese. It could be found in "Nadya tadi uwelek banget blocking $e$." Here, the participant still used Javanese words of uwelek banget instead of jelek sekali and $e$ instead of nya. These mixed and shifted languages were done unconsciously. Still, the participants did not revise it into Indonesian as he believed all group members mutually understood these words. He also stated that adding the sound of Javanese pronunciation added the underlined statement that the blocking is that bad.

All participants agreed to add emoticons, gifs, and stickers to their virtual communication. These features enabled them to replace or add their letter answers, for example, in the use of . Moreover, this emoticon is intended to give practical responses or pour their tangible expression. Choosing one of these features might also describe their identity as the message's sender, representing their ethnic group. In other words, the way they sent messages reflects their identities both as individuals and as social groups [11]. They like to be practical, fun and entertain the online situation.

Moreover, all participants were convinced that they sent funny stickers or videos to the other group members. The humor or jokes made the communication warmer and eliminated the distances among the seniors and junior ones. These funny stickers were finally ended in sticker wars which were fun to do. Besides, the funny videos were replied to by short but funny comments. They usually used the reply feature on the replied comments to avoid confusion [31]. These direct actions reverted their direct and spontaneous identity as Javanese from the east part of Java and as basketball coaches. 
These inevitable responses were related to their identities and who they were. The responses had more varieties at the collective identity level as Javanese [3]. Five participants seemed to be more committed to heritage culture maintenance than others. These five participants were regarded to have stronger ethnic identity carriers than others; for example, they were crushed to send some greetings, prayers, advice in Javanese. As they were phonologically and structurally beautiful, other group members from the different ethnic groups would like to know further about the meanings of the greetings.

\section{CONCLUSION}

This study found that Javanese basketball coaches expressed positive attitudes toward the values of Javanese as an ethnic marker and were able to maintain the importance of transmitting it in virtual communication. These findings, therefore, suggested that though the Javanese coaches as adults did not use Javanese in each virtual communication, they still emulated their Javanese ethnic identity. However, it was identified that there was a disagreement between attitudes and practices in maintaining Javanese when they met the other coaches from different ethnic groups.

It was, therefore, crucial to keep maintaining Javanese started from the possible way and the minor environment. Though it was a major ethnic group and ethnic language, Javanese urged to maintain their language though with minimum effort. Moreover, the future investigation looked forward to the younger generation in virtual communication. Therefore, any projected efforts would enhance the future of Javanese as a heritage language in this modern era.

\section{AUTHORS' CONTRIBUTIONS}

DENR wrote the manuscript and did all the analyses. DCK conducted the interviews and observations and provide data. All authors reviewed the final manuscript.

\section{ACKNOWLEDGMENTS}

We thank the ISLAGE committee and editors for performing the funding and editing.

\section{REFERENCES}

[1] M. R. Abtahian, A. C. Cohn, \& T. Pepinsky, "Modeling social factors in language shift.", International Journal of the Sociology of Language 242. 2016.139-179.

[2] A. K. Adelaar, Language documentation in the west Austronesian world and Vanuatu: An overview, In Florey, Margaret J. (ed.), Endangered languages of Austronesia, Oxford: Oxford University Press. 2010. 12-41.

[3] E. L. Zen, "Javanese Language as an Ethnic Identity Marker among Multilingual Families in Indonesia". Linguistik Indonesia. Vol 39: 1. 2021. 49-62

[4] A. Na'im, \& Hendry Syaputra. 2011. Kewarganegaraan, Suku Bangsa, Agama dan Bahasa Sehari-hari Penduduk Indonesia: Hasil Sensus Penduduk [Citizenship, Ethnicity, Religion and Daily Language of the Indonesian Population: Results.

of the Population Census 2010] Jakarta: Badan Pusat Statistik. 2010. ISBN 978-979-064- 417-5

[5] S. Musgrave, Language shift and language maintenance in Indonesia. In Language, Education and Nation-building. (2014). (pp. 87105).

[6] Z. Goebel, Language, migration, and identity: Neighborhood talk in Indonesia. Cambridge: Cambridge University Press. 2010.

[7] L. Zentz, "“'Love" the local, "use" the national, "study" the foreign: Shifting Javanese Language Ecologies in (Post-)Modernity, Postcoloniality, and Globalization". Journal of Linguistic Anthropology 24(3). 2015. 339-359.

[8] M. Ravindranath \& A. C. Cohn. "Can a language with millions of speakers be endangered?" Journal of the Southeast Asian Linguistics Society 7. 2014. 64-75.

[9] S. Hall, Who needs identity? In S. Hall \& P. D. Gay (Eds.). Questions of cultural identity. London: Sage Publications. (1996). (pp.1-17).

[10] J. Fishman, Reversing language shift: Theoretical and empirical foundations of assistance to threatened languages. Clevedon: Multilingual Matters Ltd. (1997). 
[11] P. N. L. Batu, Heritage Language and Ethnic Identity: A Study on Students' Ethnic Identity and Self-Identification in Jakarta. A Journal of Culture, English Language, Teaching \& Literature. ISSN 1414-3320 (Print), ISSN 25024914 (Online) Vol. 20 No.1. 2020.

[12] J. B. Farr, L., Harris, R., \& Smith, J. A. “It’s my language, my culture, and it's personal!" Migrant mothers' experience of language use and identity change in their relationship with their children: An interpretative phenomenological analysis. Journal of Family Issues, 39(11), 3029-3054. (2018).https://doi.org/10.1177/0192513X18764 542

[13] S. Y. Kim \& Chao, R. K. Heritage language fluency, ethnic identity, and school effort of immigrant Chinese and Mexican adolescents. Cultural Diversity Ethnic Minor Psychology, 15(1), 27-37.

(2010). https://doi.org/10.1037/a0013052.

[14] A. Deumert, "Sites of struggle and possibility in cyperspace. Wikipedia and Facebook in Afrika". In Mediatization and sociolinguistic change, edited by Jannis Androutsopoulos, 487-514. Berlin: de Gruyter. 2014.

[15] H. Kelly-Holmes, "Commentary: Mediatized spaces for minoritized languages: Challenges and opportunities". In Mediatization and sociolinguistic change, edited by Jannis Androutsopoulos, 539-543. Berlin: de Gruyter. 2014.

[16] Y. Matras, "Language and the rise of a transnational Romani identity". RomIdent Working Papers (24). http://romani.humanities.manchester.ac.uk/virtu allibrary/librarydb//web/files/pdfs/379/Paper24. pdf. 2013.

[17] I. Williams, "Downloading heritage: Vietnamese diaspora online". Paper presented at the conference Media in transition: globalization and convergence, Massachusetts Institute of Technology, Cambridge, MA. H. 10- 12 May 2002

[18] R. M. Ryan, \& Edward L. Deci. Self determination theory and the role of basic psychological needs in personality and the organization of behavior. In Oliver P. John, Richard W. Robbins \& Lawrence A. Pervin
(Eds.) Handbook of Personality: Theory and Research, 654- 678. New York: The Guilford Press. 2008.

[19] J. Potter, Digital media and learner identity: The new curatorship. New York, NY: Palgrave Macmillan. 2012.

[20] Y. Xiao-Desai, The effects of online writing on heritage language anxiety - A Bayesian analysis. In Yuan, F. \& Li,S. (eds) Classroom-Based Research on Chinese as a second language. (pp. 128 - 151 ) New York: Routledge. 2019

[21] R. Gertrud, Autochthonous heritage languages and social media: writing and bilingual practices in Low German on Facebook, Journal of Multilingual and Multicultural Development, $38: 1, \quad 35-49 . \quad 2017 . \quad$ DOI: $10.1080 / 01434632.2016 .1151434$

[22] J. Rini English in Indonesia: Its Position Among Other Languages in Indonesia. Beyond Words, 2(2), 19-40. 2014.

[23] G. Kirk, \& M. Okazawa-Rey, Identities and Social Locations: Who am I? Who are my people? In Women's lives: multicultural perspectives (6th ed., pp. 49-58). New York: McGraw-Hill. (2013).

[24] J. E. Stets, \& P.J.A Burke, Sociological approach to self and identity. Handbook of Self and Identity, 128-152. http://wat2146.ucr.edu/ papers/02a.pdf. 2003.

[25] A. C., Sparkes \& B. Smith, Qualitative Research Methods in Sport, Exercise and Health From Process to Product. Routledge. https://www.routledge.com/QualitativeResearch -Methods-inSport-ExerciseandHealthFromProcess/SparkesSmith/p/book/9 780415578356.2014.

[26] J. S. Phinney, The multigroup ethnic identity measure: A new scale for use with diverse groups. Journal of Adolescent Research, 7(2), 156-176. (1992).

[27] V. Braun, \& V. Clarke, Using thematic analysis in psychology Virginia. Qualitative Research in Psychology, 2(3), 77-101. https://doi. org/10.1191/1478088706qp063oa. 2006.

[28] J. Farr, L. Blenkiron, R. Harris, \& J. A. Smith, "It's my language, my culture, and it's personal!" 
Migrant mothers' experience of language use and identity change in their relationship with their children: An interpretative phenomenological analysis. Journal of Family Issues, 39(11), 2018. 30293054.https://doi.org/10.1177/0192513X187 64542.

[29] N. J. Smith-hefner, "Youth Language, Gaul Sociability, and the New Indonesian Middle Class". Journal of Linguistic Anthropology, $17(2), 184-203$.

https://doi.org/10.1525/jlin.2007.17.2.184.184. 2007.
[30] J. Leeman, L. Rabin, \& E. Roman-Mendoza, "Identity and activism in heritage language education". The Modern Language Journal, 95, 481495.https://doi.org/10.1111/j.15404781.2011 .01237.x.2011.

[31] B. Janeke, Netiquette_WhatsApp and Telegram. Available at: https://www.linkedin.com/pulse/netiquettewhatsapp-telegram-belinda-janeke. (2020) 